San Jose State University

SJSU ScholarWorks

Master's Theses

Master's Theses and Graduate Research

Summer 2015

\title{
The Effects of Gender, Physical Attractiveness, and Socioeconomic Status on Initial Attraction
}

Sherrie Jagolino

San Jose State University

Follow this and additional works at: https://scholarworks.sjsu.edu/etd_theses

\section{Recommended Citation}

Jagolino, Sherrie, "The Effects of Gender, Physical Attractiveness, and Socioeconomic Status on Initial Attraction" (2015). Master's Theses. 4590.

DOI: https://doi.org/10.31979/etd.33y8-kduw

https://scholarworks.sjsu.edu/etd_theses/4590

This Thesis is brought to you for free and open access by the Master's Theses and Graduate Research at SJSU ScholarWorks. It has been accepted for inclusion in Master's Theses by an authorized administrator of SJSU ScholarWorks. For more information, please contact scholarworks@sjsu.edu. 


\title{
THE EFFECTS OF GENDER, PHYSICAL ATTRACTIVENESS, AND SOCIOECONOMIC STATUS ON INITIAL ATTRACTION
}

\author{
A Thesis \\ Presented to \\ The Faculty of the Department of Psychology \\ San José State University \\ In Partial Fulfillment \\ of the Requirements for the Degree \\ Master of Arts
}

by

Sherrie Jagolino

August 2015 
(C) 2015

Sherrie Jagolino

ALL RIGHTS RESERVED 
The Designated Thesis Committee Approves the Thesis Titled

THE EFFECTS OF GENDER, PHYSICAL ATTRACTIVENESS, AND SOCIOECONOMIC STATUS ON INITIAL ATTRACTION

by

Sherrie Jagolino

APPROVED FOR THE DEPARTMENT OF PSYCHOLOGY

SAN JOSÉ STATE UNIVERSITY

August 2015

Dr. Arlene Asuncion Department of Psychology

Dr. Megumi Hosoda Department of Psychology

Dr. Mildred Alvarez Department of Psychology 


\title{
ABSTRACT \\ THE EFFECTS OF GENDER, PHYSICAL ATTRACTIVENESS, AND SOCIOECONOMIC STATUS ON INITIAL ATTRACTION
}

\author{
by Sherrie Jagolino
}

The tradeoff threshold model posits that in a heterosexual relationship, high socioeconomic status (SES) can compensate for physical unattractiveness in men, whereas physical attractiveness can compensate for low SES in women. In the present study, we attempted to provide evidence for the tradeoff threshold model. Ninety-six heterosexual participants viewed eight high and low attractive male or female stimuli photographs each attached with high or low SES descriptions. Average physical attractiveness ratings were analyzed in a 2 (physical attractiveness: high and low) x 2 (SES: high and low) repeated measures analysis of variance (ANOVA) for each gender. Women rated low SES men as more attractive than high SES men. No main effect of physical attractiveness or interaction between physical attractiveness and SES was found for women viewing men. Men provided higher ratings of attractiveness for stimuli depicting highly attractive women compared to low attractive women. Men also rated high SES women as more attractive than low SES women. Additionally, there was a significant interaction between physical attractiveness and SES. Men rated low attractive women attached with a high SES as more attractive than low attractive women attached with a low SES. Overall, we were able to provide support for the tradeoff threshold model in our analyses for men, but we were unable to confirm the model's applicability to women within our sample. 


\section{ACKNOWLEDGEMENTS}

Foremost, I would like to express a warm and sincere thank you to my advisor, Dr. Arlene Asuncion. From undergrad social psychology to a graduate master's thesis, and all the classes in between, thank you for making it interesting. What was once a design project from social psychology research methods to what is now a master's thesis was made possible with your help and guidance. A very special thanks to Dr. Megumi Hosoda for eliminating my stress in figuring out the complexity of my design and assistance with my analyses. Dr. Mildred Alvarez, your professionalism and enthusiasm for learning has taught me so much. Thank you for everything. I'd also like to thank the fellow members of my cohort for the friendship and random hangouts we've had throughout this journey. Hardeep Obhi, Megan Malmstrom, and Iya Vargas, thank you guys for your encouragement, stimulating discussions, and for making this experience a little more enjoyable. Johnny, thank you for being the big brother I never had. I will always cherish your crazy stories and life advice. Erika, our food trips and venting of frustration about random things made life much more bearable. Maru and CJ, college would not be the same without you both. Thank you for your friendship, random talks, and being there when I needed you guys. Mom, Dad, and Bianca, thank you for your endless love and guidance throughout my life. I would not be who I am today without you. Sean, thank you for always believing in me even when I didn't believe in myself. Your love, support, and encouragement enriched this entire journey. I am truly grateful. 


\section{TABLE OF CONTENTS}

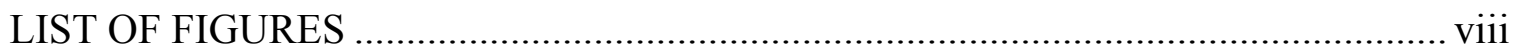

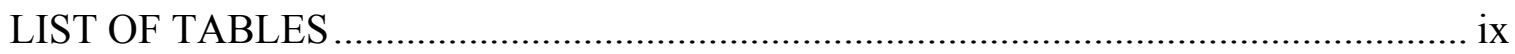

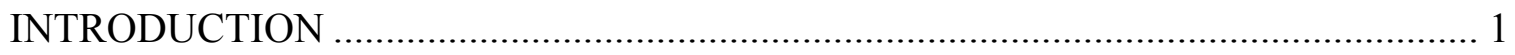

Effects of Facial Attractiveness on the Perception of Attractiveness ........................ 2

Effects of Socioeconomic Status on the Perception of Attractiveness ...................... 6

Joint Effects of Facial Attractiveness and Socioeconomic Status ............................ 8

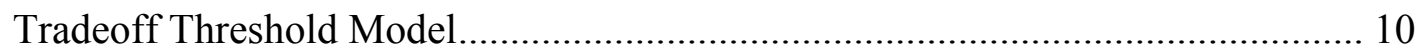

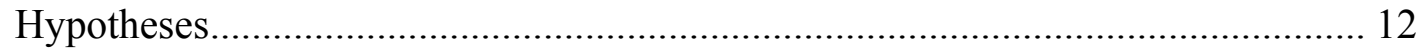

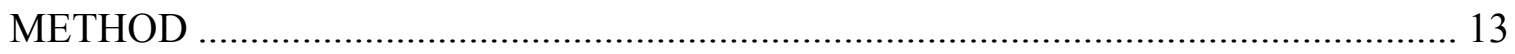

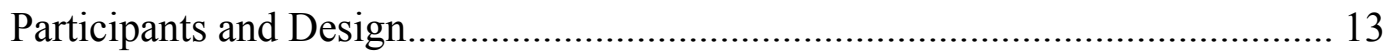

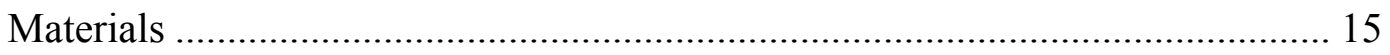

Physical Attractiveness ....................................................................... 15

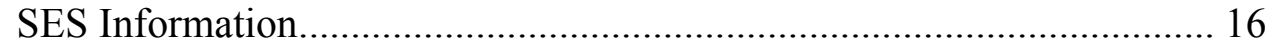

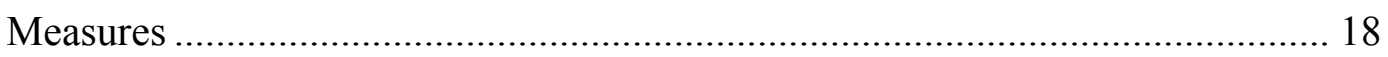

Interpersonal Attraction Measure …………………….......................... 18

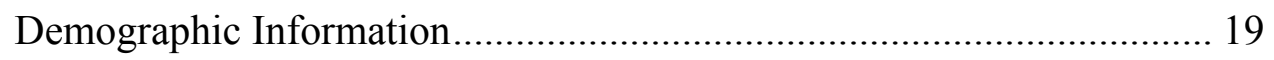

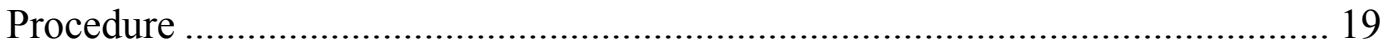

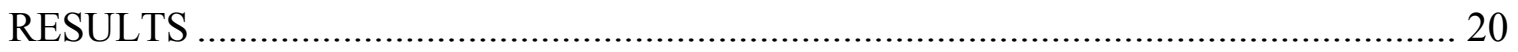

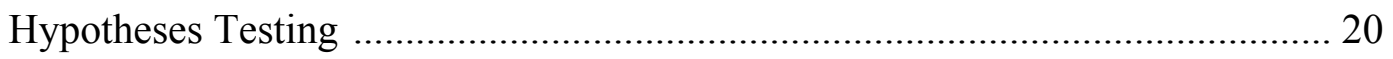

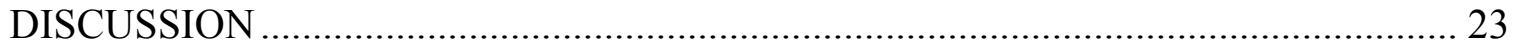

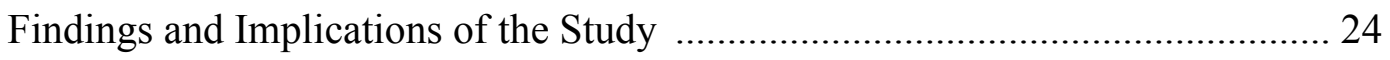




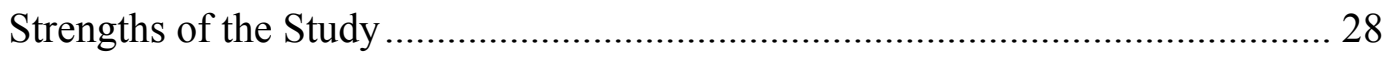

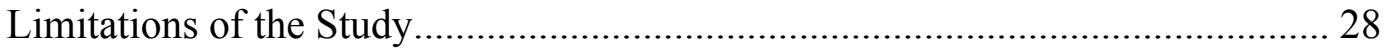

Directions for Future Research and Conclusion ................................................ 30

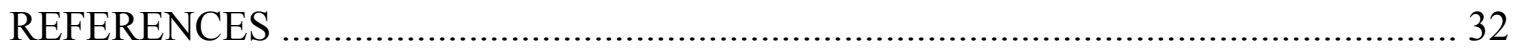

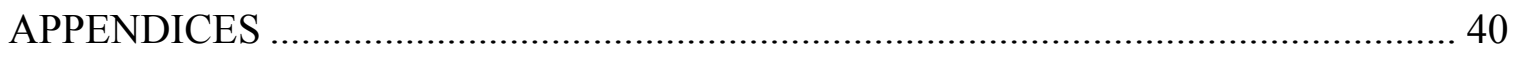

Appendix A: Sample Stimuli Facial Photographs .............................................. 40

Appendix B: Socioeconomic Status Descriptions ................................................ 41

Appendix C: Background Questionnaire .......................................................... 42

Appendix D: Modified Interpersonal Attraction Measure.................................... 44

Appendix E: Agreement to Participate in Research ............................................ 45 


\section{LIST OF FIGURES}

FIGURE 1. Tradeoff Threshold Model of Heterosexual Men's View of Women...................................................................11

FIGURE 2. Tradeoff Threshold Model of Heterosexual Women's View of Men..........12

FIGURE 3. Heterosexual Men/Women Viewing Opposite Sex Photo with SES Description.................................................... 13

FIGURE 4. Mean Attractiveness Ratings of Heterosexual Women Viewing Male

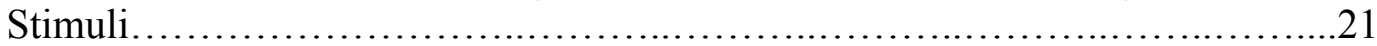

FIGURE 5. Mean Attractiveness Ratings of Heterosexual Men Viewing Female Stimuli.............................................................. 23 


\section{LIST OF TABLES}

TABLE 1. Descriptive Statistics of Sample...................................... 15

TABLE 2. Photos and SES Description Pairings for Male and Female Stimuli................................................................. 17 


\section{Introduction}

"What is beautiful is good" is a common stereotype associated with attractive individuals (Dion, Berscheid, \& Walster, 1972). Often, physically attractive people tend to receive preferential treatment and are perceived to have positive experiences across many domains in their lives (e.g., social, career, and romantic relationships; Dion, Berscheid, \& Walster, 1972). Society has embellished the rewards of being physically attractive. For instance, job applicants who are physically attractive fare better in a selection process (Hosoda, Stone-Romero, \& Coats, 2003) and receive a higher starting salary than physically unattractive applicants (McColl \& Truong, 2013; Morrow, 1990). Physically attractive waitresses receive much larger tips (Lynn, 2009) and in the court of law, criminals who are physically attractive receive lesser sentences (Breckler, Olson, \& Wiggins, 2006). In romantic relationships, attractive people are desired by others more often and are more likely to be in a relationship than their less attractive counterparts (O’Sullivan \& Vannier, 2013). Confidence, popularity, good health, along with a high earning potential and economic success are often associated with being physically attractive (Jaeger, 2011; Swami, Tovée, \& Furnham, 2008). In Hollywood, physically attractive celebrities are more likely to be associated with large houses, expensive cars, and successful lives (van Leeuwen \& Macrae, 2004). Simply put, being attractive generates positive evaluations and behavior from others.

The importance of physical attractiveness has garnered much attention from social scientists, as it is closely linked to romantic attraction (Buss, 1985). Anthropologists conducted a survey within 166 contrasting societies and concluded that romantic 
attraction was found in approximately $90 \%$ of these societies, suggesting that attraction is a ubiquitous occurrence (Jankowiak \& Fischer, 1992). One of the most important life goals and experiences that people can have is being in a satisfying and meaningful romantic relationship (Roberts \& Robins, 2000). There are a multitude of health benefits associated with being in a romantic relationship, as individuals in relationships often have a greater sense of well-being (Braithwaite, Delevi, \& Fincham, 2010; Dush \& Amato, 2005), lower blood pressure, less stress, and decreased depression rates (Holt-Lunstad, Birmingham, \& Jones, 2008). In addition, physical attractiveness serves as an indicator for good health and fertility (DeWall \& Maner, 2008). Such indicators would suggest that physical attractiveness functions as a prerequisite to potential mating relationships. In order to maximize reproductive success, various factors of attractiveness are used to assess each individual's desirability. Some factors include facial attractiveness and financial attractiveness, the latter more commonly known as socioeconomic status (SES) (Sprecher, 1989).

\section{Effects of Facial Attractiveness on the Perception of Attractiveness}

Greek philosophers and sculptors prompted the question of the true meaning of beauty in art and human features (Peck \& Peck, 1970). It was believed that beauty followed mathematical laws that displayed proportions of fixed quantities (Peck \& Peck, 1970). Thus, the emanation of Pythagoras' golden ratio was intended to define beauty in all aspects of life (Green, 2008). In the present day, the concept of beauty, or rather attractiveness, has become the subject of many scientific disciplines. Despite the vast amount of literature, very little research defines what "attractiveness" truly is. The adage 
that "beauty is in the eye of the beholder" postulates a subjective view, but objective interpretations have been identified, such as height (Pierce, 1996), weight (Carmalt, Cawley, Joyner \& Sobal, 2008), and even foot size (Fessler et al., 2005). A parallel interpretation of attractiveness, and what we will define as being physically attractive in the current research, is best defined by Morrow (1990) as "the degree to which a facial image elicits favorable reactions from others" (p. 47).

The face plays a critical role when judging someone as attractive or unattractive because facial features are the most visually attended to compared to other parts of the body (Atoum \& Al-Simadi, 2000). Facial attractiveness has also been shown to be a fairly good indicator of overall physical attractiveness (Currie \& Little, 2009; Saxton, Burris, Murray, Rowland, \& Roberts, 2009). Considering this, facial attractiveness serves as a valuable tool in understanding everyday social interactions. People believe that those with attractive faces are more kind, intelligent, successful (Foos \& Clark, 2011), and trustworthy than those with unattractive faces (Schmidt, Levenstein, \& Ambadar, 2012). Additionally, people perceive that unattractive faces possess a host of negative characteristics, such as lower levels of intelligence and kindness, both specifically deriving from the "what is ugly is bad" stereotype (Sacco, Hugenberg, \& Kiel, 2013). Furthermore, exposure to unattractive faces can stimulate the amygdala and insula, areas of the brain regularly associated with repulsive responses (Sacco, Hugenberg, \& Kiel, 2013).

The human assessment of an attractive face is associated with the perception of the extent to which a person has endured the stresses of life during development (Hume 
$\&$ Montgomerie, 2001). This ultimately leads to perceptual processing of a person's health (Hume \& Montgomerie, 2001). To illustrate, Shackelford and Larsen (1999) had 100 college students provide daily reports of whether they experienced physical symptoms, such as a runny or stuffy nose, sore throat or cough, headache, backache, nausea, muscle soreness, or jitteriness within a month's period. Cardiovascular health, or cardiac recovery time, was evaluated in one of two ways. Participants increased their heart rate through an exercise on a bicycle ergometer for one minute or by walking up and down a two-foot step for one minute. Facial photographs of each participant were taken and assessed by 37 independent raters. Results indicated that the participants who were deemed attractive complained less about their physical symptoms and had greater cardiovascular health relative to the unattractive participants (Shackelford \& Larsen, 1999).

Facial attractiveness is difficult to ignore, as people perceive attractive faces more quickly than unattractive faces (Sui \& Liu, 2009). Sui and Liu (2009) concluded that reward centers in the brain become highly activated in response to seeing an attractive face; the same reward center that responds to drugs, money, and happiness. Furthermore, the perception of facial attractiveness has been suggested to be an innate ability (Langlois, Roggman, Casey, Ritter, Rieser-Danner, \& Jenkins, 1987). Langlois et al. (1987) examined two to eight month old infants viewing photos of adult women with contrasting facial attractiveness, i.e., attractive or unattractive. Their findings indicated that all the infants looked at the attractive faces longer than the unattractive faces, illustrating that the ability to discriminate attractiveness occurs at a very young age. 
Considering that an attractive face will elicit more positive behavioral responses, women have used cosmetics to increase their facial attractiveness (Guéguen, 2008). Guéguen (2008) conducted a study that looked at women's date requests and whether the use of cosmetics played an influential role in women's facial attractiveness. Their research indicates that men approached women wearing makeup more quickly, specifically six seconds faster than those without makeup (Guéguen, 2008). This illustrates that cosmetic use can lead to the initiation of future mating relationships (Guéguen, 2008), as well as trigger the competition between women for desirable mates. Because men have placed much more emphasis on a woman's physical appearance than on some of her other characteristics, the rivalry among women to allure men through the use of their physical attributes is rooted in their views of attractiveness (Buss, 2003). Men tend to favor mates who display youthful, attractive qualities (e.g., smooth skin, soft hair) and sexual maturity (Singh, 1993b). Evolution has played a definitive role in these preferences, considering that a woman's fertile window diminishes rapidly after 30 years of age and ceases during menopause (Buss \& Schmitt, 1993). Thus, a woman's reproductive status is contingent upon age. Unlike women, men's ability to reproduce can continue well into old age, as their reproductive ability wanes gradually over a lifetime (Buss \& Schmitt, 1993). Physical features, such as symmetry (Gangestad \& Thornhill, 1998) and facial masculinity (Perrett et al., 1999), are seen as attractive in men. Nevertheless, women have also been socialized to value a man with a high social status as a potential long-term mate. 


\section{Effects of Socioeconomic Status on the Perception of Attractiveness}

Collectively, women prefer physically attractive men to physically unattractive men (Li \& Kenrick, 2006). Women look at the attractiveness of a man, such as his height, which transmits a biological clue that he has more testosterone and healthy genes to pass onto the offspring (Swami et al., 2007). However, what becomes more appealing, thus adding to a man's overall attractiveness, is his ability to provide emotional and financial support (Townsend \& Levy, 1990). Women value monetary potential in a mate because they have more of an investment in child rearing (i.e., carrying a child through a full-term pregnancy for nine months and raising the child; Ha, Berg, Engels, \& Lichtwarck-Aschoff, 2012). Choosing mates with higher financial standings allow women to claim resources for themselves as well as their children (Townsend \& Levy, 1990; Vigil, Geary, \& Byrd-Craven, 2006). The monetary resources provided by the man allow for access to better resources for health, food, and shelter. In contrast, men are aroused by visual stimuli and acquire greater gains by using the cues of fertility marked by the physical attributes of a woman (Townsend \& Levy, 1990). Evolutionary theory suggests that men are more inclined to choose women based upon their youthfulness and physical appearance because it is the easiest indicator that she will be able to reproduce successfully (Singh, 1993a).

In many societies, men make more to the dollar than women (Lips \& Lawson, 2009) and men with high social statuses are held in higher esteem (Sadalla, Kenrick, \& Vershure, 1987). To illustrate, Dewall and Maner (2008) had 46 undergraduate participants fitted with an eye-tracker to view an array of eight male and female target 
photos with varying degrees of social status. Each target photo was viewed for four seconds. Results demonstrated that participants spent more time viewing high status male targets, whereas high status female targets were viewed less than half the time. Dewall and Maner (2008) suggest that because society values high status men, more attention might be directed toward them. Alternatively, high status women do not capture as much attention (Dewall \& Maner, 2008). This may implicate that as women become more successful in their careers, the more unattractive they become to enter into a relationship with (Greitemeyer, 2007), as they are viewed more critically than less successful women (Heilman, Wallen, Fuchs, \& Tamkins, 2004). For example, Heilman, et al. (2004) had 63 undergraduate participants review a stimulus packet containing information about a job opening for Assistant Vice President of Human Resources. Participants were asked to review the three potential applicants' biographical information and to fill out a short questionnaire. Results suggested that successful women received more negative reviews, especially when they were presented in a traditionally male dominated occupation.

Previous literature has suggested that women are more likely to select mates with a higher financial standing because of the gender differences in access to power and status (Goode, 1959; Murstein, 1980). In many societies, women have less control, power, and status than men (Eagly \& Wood, 1999; Sanday, 1981). Thus, women may be more attracted by these qualities in a potential partner as a means to maximize their resources (Shoemake, 2007). Current social changes, however, have allowed women to gain greater opportunities in the work field, which have empowered them to compete 
with men for a higher SES (Sadalla, Kenrick \& Vershure, 1987). As women acquire larger financial resources, their preference for potential partners might parallel that of men (Eagly \& Wood, 1999; Ha, Berg, Engels, \& Lichtwarck-Aschoff, 2012). This means that a woman with high SES might be more influenced by a man's physical attractiveness than his SES when judging him as a potential partner. Although there is some discrepancy in the literature, much more research has provided evidence that women with high SES and successful careers consistently tend to prefer marrying men of equal or more distinguished social statuses (Buss \& Barnes, 1986; Houseknecht \& Spanier, 1980; Townsend, 1987; Townsend \& Levy, 1990).

\section{Joint Effects of Facial Attractiveness and Socioeconomic Status}

As mentioned previously, it is evident that a female's facial attractiveness serves as an indicator to men of a high quality partner. In contrast, men's socioeconomic status gives women evidence of a potential partner who can provide for her and her children. Facial attractiveness and socioeconomic status have been evaluated in literature. For example, the use of cosmetics is gender specific and is associated with superior evaluations of women (Guéguen, 2012) when used correctly. Nash, Fieldman, Hussey, Lévêque, and Pineau (2006) presented pictures of women with or without makeup. It was found that women wearing makeup are perceived to have more respectable careers and higher earning potentials than women without makeup. Additionally, in a longitudinal study, female high school students judged as facially attractive were found to acquire higher socioeconomic status than the facially unattractive female high school students (Jackson, 1992). Similarly in men, high facial attractiveness was positively 
correlated with a high SES (Hume \& Montgomerie, 2001). Furthermore, Greitemeyer (2007) had 97 participants complete an experimental questionnaire to indicate the importance of physical attractiveness, education, and income for a short-term and longterm relationship. Results revealed that both men and women placed more importance on physical attractiveness in short-term relationships, whereas income and education were more important for women in long-term relationships. Men were indifferent to women's education and income, thereby continuing to place a high value on physical attractiveness as more important in a mate in long-term relationships.

Unlike the previous studies that have used survey questionnaires and lab experiments to assess women's preferences for a potential mate, Guéguen and Lamy (2012) conducted a field experiment to assess women's receptiveness to men's date requests based on socioeconomic status. The study was conducted along the streets of France with six highly attractive male confederates. As the main purpose of the study was to evaluate the effects of socioeconomic status, attractiveness was controlled. To manipulate the social standing of each confederate, three cars (high value, middle value, low value) depicting various levels of status were used. Upon random selection of young women (between 18-25 years old) passing by, the male confederates were instructed to come out of the car and ask them for their phone number. Results revealed that the young female participants were more likely to hand out their phone numbers to the male confederates paired with a higher value car than the middle or low car value (Guéguen \& Lamy, 2012), illustrating that a high social status is an important attribute women find attractive in a potential mate. 


\section{Tradeoff Threshold Model}

Evaluations of romantic relationships have led researchers to develop various theories describing the process of mate selection (Kerckhoff \& Davis, 1962; Lewis, 1972; Reiss, 1960). The tradeoff threshold model (Townsend \& Wasserman, 1998) proposes that a man's high socioeconomic status can compensate for his low physical attractiveness, whereas a woman's high physical attractiveness can compensate for her lower socioeconomic status. It is often the case that an individual's physical attractiveness opens the door to a first date. As such, a woman's degree of physical attractiveness often becomes the initial criterion by which a man decides his level of investment in a relationship (Townsend \& Wasserman, 1998). Regardless of their education, occupation, and income, women with high physical attractiveness are, generally speaking, the most desired by men for dating, sexual relationships, and marriage (Townsend \& Wasserman, 1998). Figure 1 displays an outline of how heterosexual women are viewed by men within the tradeoff threshold model. 


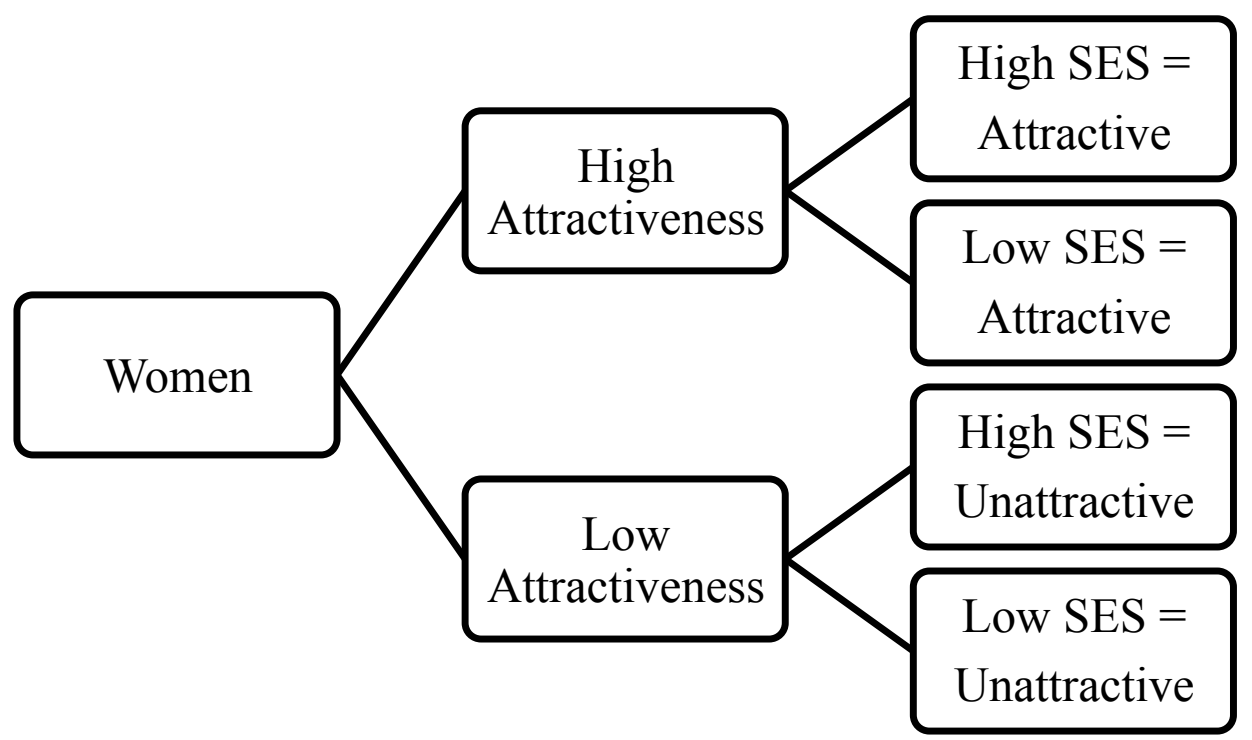

Figure 1

Tradeoff Threshold Model of Heterosexual Men's View of Women

Unlike men, women often explore nonphysical characteristics, such as men's ambition, occupation, and income. These evaluations ultimately provide women with sufficient information to decide whether or not the potential partner merits further investment (Townsend \& Wasserman, 1998). Uneducated men with low socioeconomic status are often looked down upon by women and disregarded as marital and sexual partners, regardless of their physical attractiveness (Townsend \& Wasserman, 1998). Women's evaluation by heterosexual men within the tradeoff threshold model is displayed in Figure 2. This ultimately illustrates that mating evaluations differ greatly for men and women based on the characteristics for initial acceptance by which they are regarded as a potential mate. 


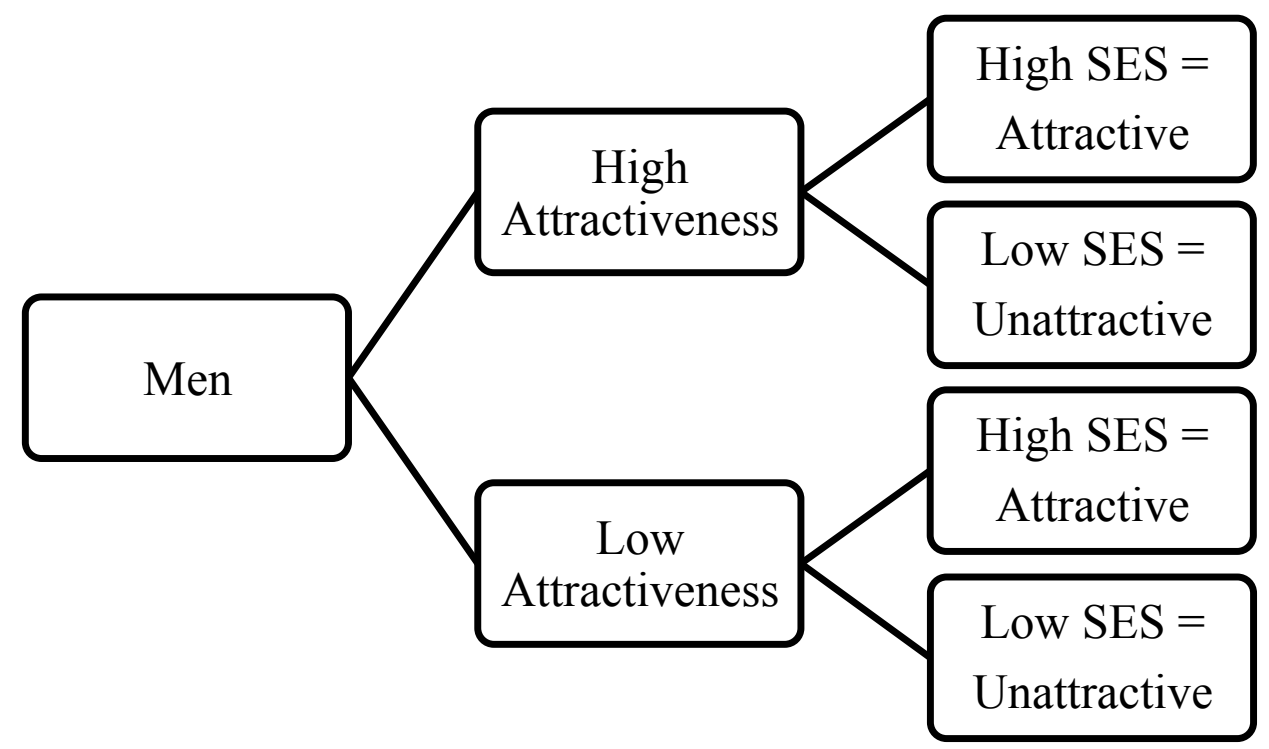

Figure 2

Tradeoff Threshold Model of Heterosexual Women's View of Men

\section{Hypotheses}

The current study examined the relationship between gender, physical attractiveness, and socioeconomic status in assessing attractiveness in heterosexual relationships. Additionally, we used the tradeoff threshold model as a theoretical paradigm to explain the gender differences in evaluating potential partners. We manipulated SES and physical attractiveness to assess participants' perception of initial attraction to a potential romantic partner. Thus, we tested the following hypotheses:

Hypothesis 1: There will be a main effect of SES such that women will give higher ratings of attractiveness to high SES men than low SES men, regardless of their physical attractiveness. 
Hypothesis 2: There will be a main effect of physical attractiveness such that men will rate physically attractive women more attractive than physically unattractive women, regardless of their SES.

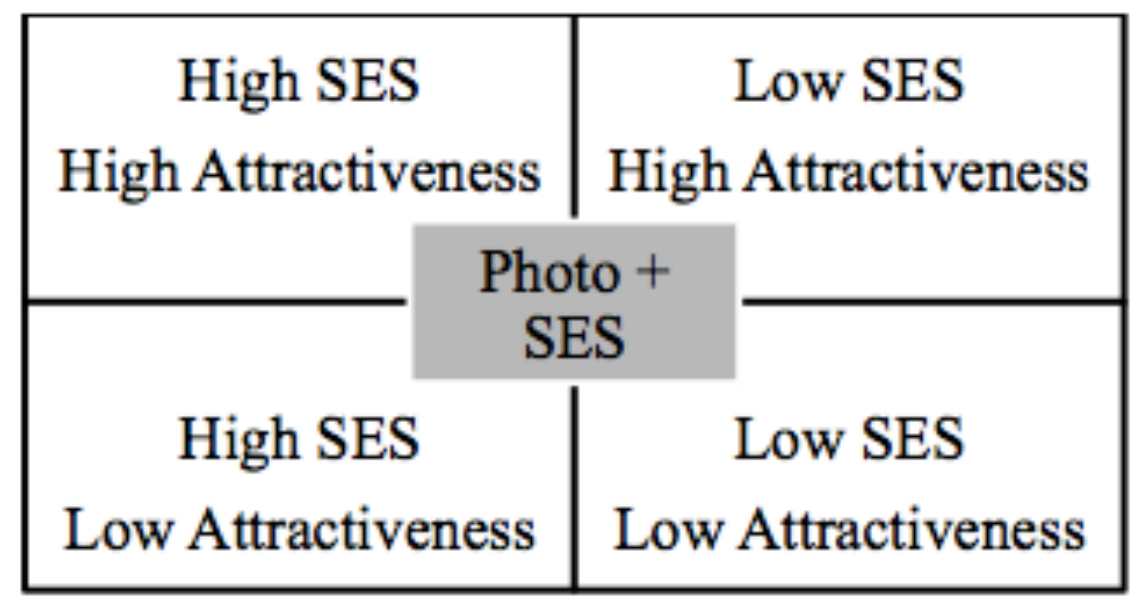

Figure 3

Heterosexual Men/Women Viewing Opposite Sex Photo with SES Description

\section{Method}

\section{Participants and Design}

We employed a 2 (participant gender: male and female) $\times 2$ (physical attractiveness: high and low) $\times 2$ (SES: high and low) mixed factorial design. Physical attractiveness and SES of the stimuli were the within-subject factors. The gender of the participants was a between-subjects factor. The dependent variable was the attractiveness ratings of the stimuli.

Participants were recruited from San José State University's research pool and various psychology courses. Students were compensated with participation credit as a 
requirement for an introductory psychology course or extra credit for other psychology classes. Additional participants were recruited from Craigslist ad postings. Those recruited from Craigslist received no compensation. Advertisements containing the link to the study were posted in the volunteer section on Craigslist. Those who did not complete more than $90 \%$ of the study or were under the age of 18 were excluded from analyses. In addition, participants who identified themselves as bisexual or homosexual were omitted, as the current study focused on heterosexual individuals. A total of 96 participants comprised the final sample for the analyses $\left(M_{\text {age }}=32.24\right.$ years, $S D=15.15$ years). Table 1 presents the demographic information of the participants. 
Table 1

Descriptive Statistics of Sample

\begin{tabular}{|c|c|c|}
\hline & $n$ & $\%$ \\
\hline \multicolumn{3}{|l|}{ Gender } \\
\hline Male & 26 & 27.1 \\
\hline Female & 70 & 72.9 \\
\hline \multicolumn{3}{|l|}{ Age } \\
\hline $18-26$ & 54 & 56.3 \\
\hline $27-35$ & 10 & 10.4 \\
\hline $36-44$ & 13 & 13.5 \\
\hline $45+$ & 19 & 19.8 \\
\hline \multicolumn{3}{|l|}{ Ethnicity } \\
\hline White & 50 & 52.1 \\
\hline Black & 6 & 6.3 \\
\hline Asian & 11 & 11.5 \\
\hline Pacific Islander & 2 & 2.1 \\
\hline Hispanic/Latino & 23 & 24.0 \\
\hline Other & 4 & 4.2 \\
\hline \multicolumn{3}{|l|}{ Current Annual Income } \\
\hline Not Working & 25 & 26.0 \\
\hline $1-20,000$ & 25 & 26.0 \\
\hline $20,001-40,000$ & 10 & 10.4 \\
\hline $40,001-60,000$ & 10 & 10.4 \\
\hline $60,001-80,000$ & 9 & 9.4 \\
\hline $80,001+$ & 14 & 14.6 \\
\hline
\end{tabular}

\section{Materials}

Physical attractiveness. The facial photographs used in this study were obtained from the FACES database of the Max Planck Institute for Human Development (Ebner, Riediger, \& Lindenberger, 2010) based in Germany. Male and female stimuli were photographed from the shoulders and above wearing a simple gray $\mathrm{T}$-shirt standing behind a gray background (see Appendix A). Prior research has noted that facial 
expressions, such as smiling, may influence a participant's initial impression (Schmidt, Levenstein, \& Ambadar, 2012). Therefore, photographs displaying neutral expressions were used.

In addition, the perceived ethnicity of the stimuli may influence the judgment of attractiveness (Cross \& Cross, 1971). For this reason, the ethnicity of the stimuli was controlled to be Caucasian (White). Previous studies have shown that makeup is used to increase a woman's physical attractiveness (Guéguen, 2008). Excessive makeup, however, may negatively affect a woman's perceived performance in career-related positions (Cox \& Glick, 1986). In this study, the women in the photographs shown wore very minimal to no makeup.

In order to ensure the validity of the level of physical attractiveness of the facial images, a pilot study was conducted in a between-subjects design on the male and female stimuli photographs. An independent group of 133 women and 71 men were asked to rate whether the facial photographs of the opposite sex stimuli were physically attractive or physically unattractive as quickly as possible on a 2-point scale $(1=$ physically unattractive; 2 = physically attractive). The results from the pilot study rendered two categories of the stimuli's facial photographs as physically attractive or physically unattractive. The results of the pilot study showed effective manipulation of the stimuli. From the pilot study, we randomly selected eight stimuli photos for each gender to implement into our experiment.

SES information. Socioeconomic descriptions include information pertaining to type of occupation and annual gross income (see Appendix B). The pool of occupations 
was chosen at random, with adequate gender variability for use in both male and female conditions (e.g., retail sales worker, waiter/waitress, medical doctor, corporate lawyer). Annual salary information was retrieved from the United States Bureau of Labor Statistics from its most current update (U.S. Bureau of Labor Statistics, 2014). Similarly, we tested the SES descriptions in a pilot study of 86 participants to establish an accord with what was conventionally known as high or low status. Participants were shown the title of the occupation and annual salary. Participants were instructed to select from one of two choices: high status or low status. Results from the pilot study showed effective manipulation of the SES descriptions. In this study, a high SES was considered to be an income of more than $\$ 100,000 /$ year, while a low SES was categorized as an income of less than $\$ 30,000 /$ year. Pairings of the SES descriptions with photographs were two high attractive stimuli paired with two high SES, two low attractive stimuli paired with two low SES, two high attractive stimuli paired with two low SES, and two low attractive stimuli paired with two high SES. Table 2 displays the pairings of the four high and four low attractive photos with four high and four low SES descriptions.

Table 2

Photos and SES Description Pairings for Male and Female Stimuli

\begin{tabular}{lll}
\hline Attractiveness & Low SES & High SES \\
High Attractive & 1; Retail Sales Worker & 3; Lawyer $(\$ 113,530)$ \\
Photos & $(\$ 21,410)$ & \\
& $7 ;$ Waiter $(\$ 18,540)$ & 6; Dentist $(\$ 149,310)$ \\
Low Attractive & 5; Library Assistant $(\$ 26,800)$ & 2; Financial Manager \\
Photos & & $(\$ 109,740)$ \\
& 8; Bank Teller $(\$ 24,940)$ & $4 ;$ Medical Doctor $(\$ 187,200)$ \\
\hline
\end{tabular}

Note. \# designates the order in which stimuli photos were shown. 
Previous studies have shown that perceptions of an individual are influenced by the stereotypes affiliated with names (Erwin, 1993; Harari \& McDavid, 1973) and traits (Asch, 1946). For example, Erwin (1993) found that participants evaluated the names attached to female photographs more positively than the female photograph alone. Furthermore, Asch (1946) found that warm and cold traits were essential in forming an impression and had the ability to transform a participant's impression when warm and cold traits interchanged. Exclusion of these additional factors from the descriptions allowed for the participant to base their perceptions solely on the facial photograph and SES description.

\section{Measures}

Interpersonal Attraction Measure. The perception of physical attractiveness was used using the Interpersonal Attraction Measure (Lemay, Clark, \& Greenberg, 2010), which was designed to assess multiple dimensions of social/romantic relationships, such as perceived interpersonal traits, motivation to bond with the self, affiliation motivation, and perception of responsiveness using an 11-item scale. A modified version of the measure (see Appendix D) was used in our study and served as our dependent variable item pertaining to the judgment of a target's physical attractiveness ("How physically unattractive or physically attractive is this person?"). Participants responded to the item using a 7-point Likert-type scale, ranging from 1 (very unattractive) to 7 (very attractive).

Four other items, such as rating of the target's personality including kindness, generosity, extraversion, and warmth, and remaining items on the measure, such as extent of liking or disliking, treatment of the target, and interests in getting to know the target, 
were employed in the study as filler questions. These items were not analyzed, as they were not of immediate interests.

Demographic information. A background questionnaire asked participants for their basic demographic information, such as age, gender, ethnicity, sexual orientation, and current annual income (see Appendix C).

\section{Procedure}

Participants completed this study online. Those recruited from Craigslist viewed an advertisement in the volunteer section with the following description:

Hello. We are conducting a survey on first impressions and we would greatly appreciate your participation. In the survey, you will be shown various photographs and answer questions based upon your perception of the photograph. Please note that participation in the survey is completely voluntary and will remain anonymous/confidential. There will be no repercussions if you choose to withdraw from the survey at any time. If there are any questions/comments/concerns you have, you may indicate it in the comment box at the end of the survey. Thank you for your participation!

Upon clicking the link to the study, participants were informed that they would be taking part in a 10-15 minute study about first impressions. Prior to beginning the study, participants read a consent form and electronically provided their consent. Upon introduction to the study, participants were asked the reason for their participation, which varied between "Psychology 001 REP credit," "Extra credit for class," or "Other." After their individual selection, part one of the background questionnaire was then shown. Participants were instructed to answer all questions pertaining to their age, gender, ethnicity, and sexual orientation. This information allowed the program to assign them to one of two conditions: female stimuli with photo and SES description or male stimuli with photo and SES description. Participants saw and rated eight opposite sex high/low 
attractive facial photographs and high/low SES descriptions. SES descriptions were listed below the facial photograph. Questions from the Modified Interpersonal Attraction Measure were depicted below each photograph and SES description. Following the completion of the study, participants then completed a demographic questionnaire and were allowed to state any questions or comments they had, after which they were provided with a debriefing page stating the true intent of the study. Participants were then thanked for their time and contribution to psychological research.

\section{Results}

\section{Hypotheses Testing}

Our first hypothesis predicted that women would rate high SES men as more attractive than low SES men, regardless of their level of physical attractiveness. A 2 (physical attractiveness: high and low) x 2 (SES: high and low) repeated-measures analysis of variance (ANOVA) was conducted on the data from women viewing male stimuli. The dependent variable was the average physical attractiveness rating of two pictures from each condition depicted in Figure 3. The results showed a statistically significant main effect of SES, $F(1,69)=9.72, p=.003$. This outcome suggested that women were indeed influenced by the differences in men's SES; however, the specific outcome was not as expected. Low SES male stimuli $(M=4.15, S D=0.93)$ received higher ratings of attractiveness than high SES male stimuli $(M=3.99, S D=0.91)$. There was no main effect of physical attractiveness, $F(1,69)=1.80, p=.185$. In addition, no interaction between physical attractiveness and SES, $F(1,69)=.315, p=.577$, was found for women viewing male stimuli. Thus, Hypothesis 1 was not supported. A graph 
displaying the mean attractiveness ratings as a function of SES and physical attractiveness is presented in Figure 4.

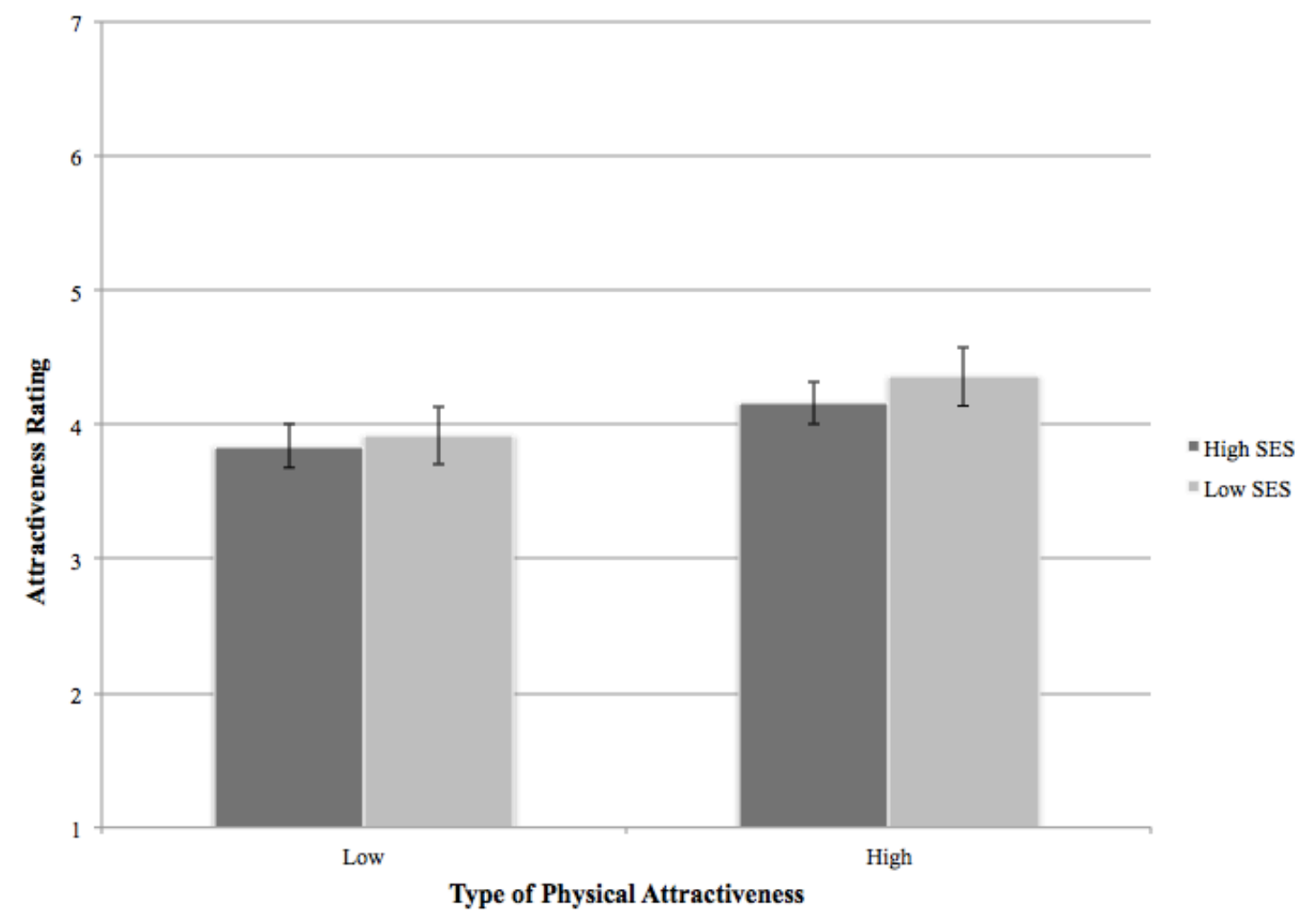

Figure 4

Mean Attractiveness Ratings of Heterosexual Women Viewing Male Stimuli. Error bars represent standard errors.

In Hypothesis 2, we expected that there would be a main effect of attractiveness for men viewing the female stimuli. A 2 (physical attractiveness) x 2 (SES) repeated measures ANOVA showed a significant main effect of attractiveness, $F(1,25)=9.85, p=$ .004. Results indicated that the high attractive female stimuli $(M=4.57, S D=0.88)$ received higher ratings of attractiveness than the low attractive female stimuli $(M=2.97$, $S D=1.01)$. These results were consistent with Hypothesis 2. Furthermore, a main effect 
was found for SES, $F(1,25)=71.56, p<.001$. High SES women $(M=4.09, S D=0.99)$ were rated as more attractive than low SES women $(M=3.77, S D=1.09)$. Our results also indicated a significant interaction between physical attractiveness and SES, $F(1,25)$ $=14.67, p<.001$. We examined this interaction further. A paired samples $t$-test revealed a significant effect of SES for low attractive female stimuli, $t(25)=4.62, p<.001$. Low attractive women with high SES $(M=3.56, S D=1.31)$ were rated as more attractive than low attractive women with low SES $(M=2.55, S D=1.40)$. These results suggest that an unattractive woman can be considered more attractive to a man if she is financially successful (i.e., if she has high SES). Generally, high attractive women with low SES $(M=4.85, S D=1.06)$ were rated as more attractive than high attractive women with high $\operatorname{SES}(M=4.60, S D=1.07)$. However, these results were not statistically significant, $t(25)=-1.33, p=.197$. Figure 5 displays the mean attractiveness ratings for these outcomes. 


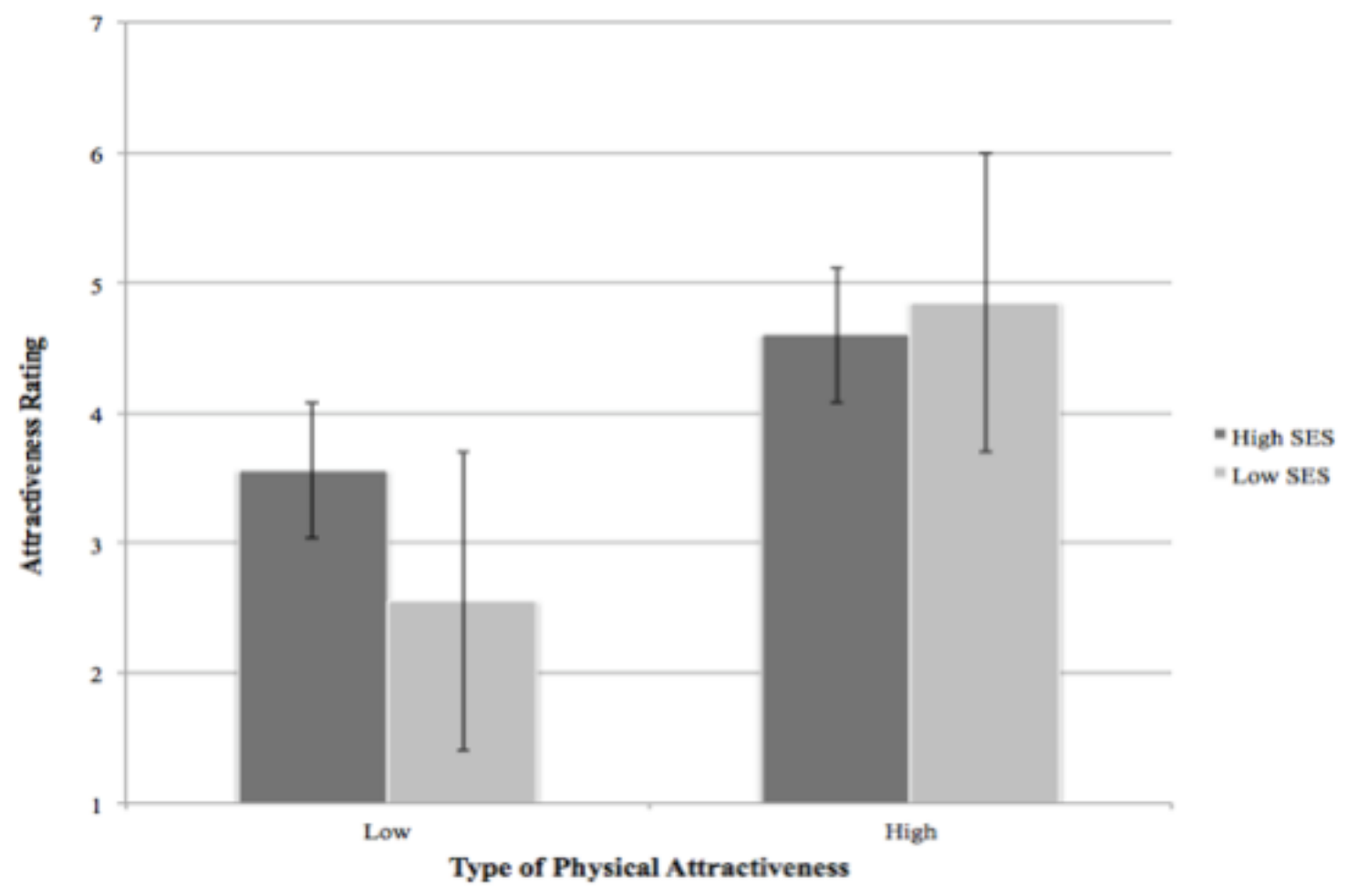

Figure 5

Mean Attractiveness Ratings of Heterosexual Men Viewing Female Stimuli. Error bars represent standard errors.

\section{Discussion}

The present study tested the proposed applicability of the tradeoff threshold model to heterosexual men and women. According to this model, in the perception of attractiveness, a man's SES can compensate for his low physical attractiveness, whereas a woman's high physical attractiveness can compensate for her low SES. Due to the nature of our study, we aimed to explore the model from a social standpoint, examining if one specific social factor, socioeconomic status, could affect the judgment of attractiveness. 


\section{Findings and Implications of the Study}

Hypothesis 1 proposed that the tradeoff threshold model would hold true for heterosexual women in their preference for high SES men, irrespective of physical attractiveness. However, our findings did not support this prediction. Rather, a main effect of SES was found, suggesting that women were affected by the differences in men's SES, although it was not in the hypothesized direction. Low SES men received higher ratings of attractiveness than high SES men. Our findings are inconsistent with previous research by Eastwick and Finkel (2008) who found that on a list of stated preferences in a potential mate, women placed greater value on a man's social status than on his physical attractiveness. Likewise, Guéguen and Lamy (2012) found similar results in a field experiment, wherein women were more likely to date a man with an expensive car (high SES) than a middle or low car value (low SES). Additionally, an eye-tracker found women focusing their superior fields of vision on high status men suggesting that high status men are more likely than low status men to gain the attention of women (DeWall \& Maner, 2008).

Our findings also contradict the notion of simplified views of sex differences in mating. Such views propose that women tend to place a higher value on SES because of the need for financial security from a man in order to raise children (Trivers, 1972). This need for an "economic guarantee" is a product of the mismatched division of power and status held by women throughout many societies (Sanday, 1981). Consequently, acquiring more resources would aid in raising children. If, however, a woman is able to acquire her own financial resources, she may change her preference to mimic that of 
men's preference for physically attractive women (Eagly \& Wood, 1999; Ha, Berg, Engels, \& Lichtwarck-Aschoff, 2012), regardless of SES.

Alternatively, our findings showed that women gave higher mean ratings of attractiveness to the low SES male stimuli, inconsistent with past research discussed above. Perhaps one reason for this finding may be that the women in our sample may have higher SES than in previously published literature (DeWall \& Maner, 2008; Guéguen \& Lamy, 2012). This was not the case as further analyses revealed that more than $50 \%$ of our sample of heterosexual women earned a salary of less than $\$ 20,000 /$ year. Instead, the lack of support for our first hypothesis regarding heterosexual women may indicate a possible shift in women's evaluations such that men with low SES are now more likely to be considered as potential mates. Women today may not need to rely on the financial status of a man as an "economic guarantee" because they are capable of earning their own income, as $73 \%$ of our sample of women indicated that they were employed. Thus, women may be able to evaluate men on other aspects of mate potential rather than SES alone.

In comparison to heterosexual females, we obtained different findings for heterosexual males. Hypothesis 2 predicted that men would prefer physically attractive women regardless of their SES. Results demonstrated that heterosexual male participants gave higher attractiveness ratings to high attractive female stimuli than to low attractive female stimuli. This finding provides support for the tradeoff threshold model and is consistent with literature in the field stating that men place a greater value on physical attractiveness in a potential mate (Buunk, Dijkstra, Fetchenhauer, \& Kenrick, 2002; Li et 
al., 2013; Meltzer, McNulty, Jackson, \& Karney, 2014; Sprecher, Sullivan, \& Hatfield, 1994). Men also gave higher attractiveness ratings to high SES female stimuli than to low SES female stimuli. In addition, a significant interaction was found between attractiveness and SES such that a physically unattractive woman can become more attractive to a man if she is financially successful. This particular finding was unexpected, as past research has illustrated that preferences for high status partners is mostly held by heterosexual women (Ha, van den Berg, Engels, \& Lichtwarck-Aschoff, 2012; Lippa, 2007; Sadalla, Kenrick, \& Vershure, 1987) and that high status women are often unable to capture the attention of heterosexual men (DeWall \& Maner, 2008). It has also been reported that women are viewed more critically as they become more successful in their careers and acquire higher financial status (Heilman et al., 2004). Additionally, successful women are considered to be "unattractive" people with whom to enter into a relationship with (Greitemeyer, 2007). Interestingly, the low attractive and high SES female stimuli were rated as more attractive than the high attractive and high SES female stimuli. This may suggest that the negative views toward high SES women, as past research has reported (Heilman et al., 2004; Greitemeyer, 2007), are mainly directed toward physically attractive women, but not physically unattractive women. Thus, our findings seem to indicate that one way for physically unattractive women to become "attractive" is to obtain a high SES. This could provide evidence of a possible change in men's evaluation of potential mates.

In recent years, television and movie audiences have seen an influx of strong, independent, financially successful, and career minded women (e.g., Scandal, Revenge, 
How to Get Away with Murder, Grey's Anatomy, The Good Wife, The Hunger Games, Divergent). The media can be very influential in forming our views on many issues (e.g., Condry, 1989). This change in the manner in which women are often portrayed may have influenced our sample of heterosexual men's evaluations to consider highly successful (i.e., high SES) women as potential partners, even when such women are portrayed in a relatively less physically attractive manner. Also, a high SES is often perceived to denote intelligence ( $\mathrm{Li}$ et al., 2002). This view may stem from the notion that education (and perhaps intelligence) is positively correlated with income. Intelligence in a potential mate is desired and perhaps even required as a characteristic relating to the ability to function well in everyday life as well as possessing the ability to nurture children (Li, Bailey, Kenrick, \& Lisenmeier, 2002). Men may have adapted to favor intelligent women more than previous literature might suggest.

The shift in men's evaluations can be seen in entertainment news. For example, George Clooney, formerly known as one of the world's most eligible bachelors, made recent headlines with his marriage to Amal Alamuddin, a respected and powerful lawyer in her own right. Clooney's previous relationships involved several models and actresses known for their physical beauty, but unfortunately for the women involved, the relationships never amounted to marriage. It was not until his recent relationship with an activist lawyer that Clooney considered breaking his bachelorhood and marrying a woman for her intelligence and her ability to achieve her own high financial status. In his own assessment, Clooney stated that he was "marrying up" (Rothman, 2014). The publicity that surrounded George Clooney's marriage, along with television shows and 
movies depicting intelligent and career-minded women, may have contributed to the change in male mate preferences that we captured in our analyses.

\section{Strengths of the Study}

One strength of our study was that it provided support for the tradeoff threshold model's applicability to heterosexual men. Much of the literature regarding mate preferences has consistently stated that men place an emphasis on the physical attractiveness of a potential partner, as it is rooted in their biology to desire a woman based on her ability to reproduce children (Buss, 2003; Singh, 1993b). We were able to find parallel results that men value attractiveness in a woman.

Compared to Ha et al. (2012), we eliminated additional variables, such as names and traits (Erwin, 1993; Asch, 1946), in the descriptions associated with the male and female stimuli photographs. This effort allowed us to focus only on the effects of physical attractiveness and SES. The exclusion of these extra variables provides another strength to our study. In addition, the male and female stimuli we used were photographed wearing a gray neutral shirt and behind a gray background. Stimuli were photographed from the shoulders and above. This allowed for the elimination of additional variables, such as body weight (Swami \& Tovée, 2005), height (Pierce, 1996), and colors (Hammett, Issler, \& Bashore, 2014) to be factored into a participant's judgment.

\section{Limitations of the Study}

The assessment of photographs for the purpose of determining a potential dating partner is not reflective of the nature of real world romantic relationships. There are 
many other variables to consider, such as personality, values, and desire for a short or long-term relationship. Certainly, considerations of these multiple factors would make it difficult to mimic that of a real life relationship in a lab setting. Another limitation of our study was highlighted in important comments made by study participants. Many of our participants listed in the comment box that the photographs exposed them to persons of only one ethnicity (i.e., White) and that they would have preferred exposure to persons of multiple ethnic backgrounds. Past research has shown that culture can affect attraction (Malach Pines, 2001) for both the perceiver and the perceived (Bruce, Beard, Tedford, Harman, \& Tedford, 1997). In addition, a shift in public opinion has resulted in greater acceptance of people engaging in interracial relationships (Carroll, 2007). Considering the diverse ethnic background in our sample, many participants felt that limiting the exposure to just White stimuli was not indicative of their social surroundings.

The male and female stimuli photographs used in our study were of persons under 30 years of age at the time the photographs were taken. Sappenfield and Baloch (1970) found that perceiving others who were viewed as more physically similar (e.g., age), the more attractive they appeared to be. The age ranges of the persons depicted in the stimuli photographs were similar to the ages of the majority of our sample. However, it presented a limitation for the participants who were older and who may have preferred viewing a photograph of a person of similar age to themselves. We also obtained more female participants than male participants. Our analyses for men may not be an accurate representation of how other men feel and may be just applicable to these 26 men who participated in our study. 
Another limitation would be that personality characteristics are often associated with occupations (Barrick \& Mount, 1991). For example, extroversion is needed in occupations that require social interactions, such as in management and sales (Barrick \& Mount, 1991). As such, the occupations we used in our study (e.g., retail sales worker, medical doctor, waiter/waitress) may have inadvertently influenced participant's judgment of attractiveness. These limitations, however, can also provide us a sense of direction for future research.

\section{Directions for Future Research and Conclusion}

Future research should attempt to replicate our findings to see if the shifts in mate preferences for heterosexual men and women truly exist. We also suggest that when assessing SES in conjunction with physical attractiveness, researchers should pre-test for biases participants may have regarding certain occupations. If such biases exist, exposure to just annual salary alone may reduce the influence of extraneous variables.

Additionally, we suggest including more intermediate annual incomes (e.g., $\$ 50,000 /$ year) as opposed to only high and low annual incomes in order to attain a more realistic view of varying SES range. We propose further analyses on the relationship between a participant's income and their ratings of attractiveness, such as whether persons having similar or different SES to one's self are considered attractive qualities in a potential mate.

In addition, literature on mating patterns and behaviors has focused on heterosexual relationships. Accordingly, we propose that future research expand the literature on the homosexual population and the effects of SES on initial attraction. We 
also suggest future research to assess if participants are currently dating for the purpose of having a short-term relationship or a long-term relationship. These two dating styles may indicate different perspectives in what is viewed as initially attractive (Townsend \& Levy, 1990). Lastly, we suggest conducting future research outside a lab setting to analyze mate preferences in the real world. While there are important benefits to lab studies in allowing for control and manipulation of selected variables, it is also the case that lab studies can become too artificial. Determining physical attractiveness and choosing a potential mate would be best understood in the real world.

In conclusion, the present study aimed to provide support for the tradeoff threshold model's applicability to heterosexual men and women. We did not find support for Hypothesis 1 in that heterosexual women did not find high SES men as the most attractive. However, for heterosexual men, our results did support Hypothesis 2 in that men were found to prefer a physically attractive woman to a physically unattractive woman. We also found new evidence that may suggest that a physically unattractive woman can become more attractive to a man if she has a high SES. Our findings have implications for how societal changes can bring about shifts in how people rate initial attractiveness. As found in the present study, we were able to reveal possible new trends in how SES could affect initial attractiveness. Overall, we hope our study enlightens the current status of information about how we selectively seek out potential mates. 


\section{References}

Asch, S. E. (1946). Forming impressions of personality. The Journal of Abnormal and Social Psychology, 41, 258-290.

Atoum, A. O., \& Al-Simadi, F. A. (2000). The effect of presentation modality on judgments of honestly and attractiveness. Social Behavior and Personality, 28, 269-278.

Barrick, M. R., \& Mount, M. K. (1991). The big five personality dimensions and job performance: A meta-analysis. Personnel Psychology, 44, 1-26.

Braithwaite, S. R., Delevi, R., \& Fincham, F. D. (2010). Romantic relationships and the physical and mental health of college students. Personal Relationships, 17, 1-12.

Breckler, S. J., Olson, J. M., \& Wiggins, E. C. (2006). Social Psychology Alive. Belmont, CA: Thomson Learning, Inc.

Bruce, A. J., Beard, K. W., Tedford, S., Harman, M. J., \& Tedford, K. (1997). African Americans' and Caucasian Americans' recognition and likeability responses to African American and Caucasian American faces. Journal of General Psychology, 124, 143-156.

Buss, D. (1985). Human mate selection. American Scientist, 73, 47-51.

Buss, D. (2003). The evolution of desire. New York, NY: Basic Books.

Buss, D. M., \& Barnes, M. (1986). Preferences in human mate selection. Journal of Personality and Social Psychology, 50, 559-570.

Buss, D. M., \& Schmitt, D. P. (1993). Sexual strategies theory: An evolutionary perspective on human mating. Psychological Review, 100, 204-232.

Buunk, B., Dijkstra, P., Fetchenhauer, D., \& Kenrick, D. (2002). Age and gender differences in mate selection criteria for various involvement levels. Personal Relationships, 9, 271-278.

Carmalt, J. H., Cawley, J., Joyner, K., \& Sobal, J. (2008). Body weight and matching with a physically attractive romantic partner. Journal of Marriage and Family, 70, 1287-1296.

Carroll, J. (2007). Most Americans approve of interracial marriages: Blacks more likely than whites to approve of black-white unions. Gallup Poll. Retrieved from 
http://www.gallup.com/poll/28417/most-americans-approve-interracialmarriages.aspx.

Condry, J. (1989). The psychology of television. Hilldale, NJ: Lawrence Erlbaum Associates.

Cox, C. L., \& Glick, W. H. (1986). Resume evaluations and cosmetics use: When more is not better. Sex Roles, 14, 51-58.

Cross, J. F., \& Cross, J. (1971). Age, sex, race, and the perception of facial beauty. Developmental Psychology, 5, 433-439.

Currie, T. E., \& Little, A. C. (2009). The relative importance of the face and body in judgments of human physical attractiveness. Evolution and Human Behavior, 30, 409-416.

DeWall, C. N., \& Maner, J. K. (2008). High status men (but not women) capture the eye of the beholder. Evolutionary Psychology, 6, 328-341.

Dion, K., Berscheid, E., \& Walster, E. (1972). What is beautiful is good. Journal of Personality and Social Psychology, 24, 285-290.

Dush, C. K., \& Amato, P. R. (2005). Consequences of relationship status and quality for subjective well-being. Journal of Social and Personal Relationships, 22, 607-627.

Eagly, A. H., \& Wood. W. (1999). The origins of sex differences in human behavior: Evolved dispositions versus social roles. American Psychologist, 54, 408-423.

Eastwick, P. W., \& Finkel, E. J. (2008). Sex differences in mate preferences revisited: Do people know what they initially desire in a romantic partner? Journal of Personality and Social Psychology, 94, 245-264.

Ebner, N. C., Riediger, M., \& Lindenberger, U. (2010). FACES-A database of facial expressions in young, middle-aged, and older women and men: Development and validation. Behavior Research Methods, 42, 351-362.

Erwin, P. G. (1993). First names and perceptions of physical attractiveness. Journal of Psychology: Interdisciplinary and Applied, 127, 625-631.

Fessler, D.T., Nettle, D., Afshar, Y., de Andrade Pinheiro, I., Bolyanatz, A., Mulder, M.B., ...Zbarauskaite, A. (2005). A cross-cultural investigation of the role of foot size in physical attractiveness. Archives of Sexual Behavior, 34, 267-276.

Foos, P. W., \& Clark, M. C. (2011). Adult age and gender differences in perceptions of 
facial attractiveness: Beauty is in the eye of the older beholder. The Journal of Genetic Psychology, 172, 162-175.

Gangestad, S. W., \& Thornhill, R. (1998). Menstrual cycle variation in women's preference for the scent of symmetrical men. Proceedings of the Royal Society of London B, 262, 727-733.

Goode, W. J. (1959). The theoretical importance of love. American Sociological Review, $24,38-47$.

Green, J. D. (2008). Is research on beauty only skin deep? Review of the psychology of physical attraction. The Journal of Social Psychology, 148, 379-382.

Greitemeyer, T. (2007). What do men and women want in a partner? Are educated partners always more desirable? Journal of Experimental Social Psychology, 43, $180-194$.

Guéguen, N. (2008). Brief report: The effects of women's cosmetics on men's approach: An evaluation in a bar. North American Journal of Psychology, 10, 221-228.

Guéguen, N., \& Lamy, L. (2012). Men's social status and attractiveness: Women's receptivity to men's date requests. Swiss Journal of Psychology, 71, 157-160.

Ha, T., Berg, J. E. M., Engels, R. E., \& Lichtwarck-Aschoff, A. (2012). Effects of attractiveness and status in dating desire in homosexual and heterosexual men and women. Archives of Sexual Behavior, 41, 673-682.

Hammett, J. F., Issler, E. J., \& Bashore, H. E. (2014). The effect of the color red on hirability and attractiveness. Psi Chi Journal of Psychological Research, 19, 20-27.

Harari, H., \& McDavid, J. W. (1973). Name stereotypes and teachers' expectations. Journal of Educational Psychology, 65, 222-225.

Heilman, M. E., Wallen, A. S., Fuchs, D., \& Tamkins, M. M. (2004). Penalties for success: Reactions to women who succeed at male gender-typed tasks. Journal of Applied Psychology, 89, 416-427.

Holt-Lunstad, J., Birmingham, W., \& Jones, B. Q. (2008). Is there something unique about marriage? The relative impact of marital status, relationship quality, and network social support on ambulatory blood pressure and mental health. Annals of Behavioral Medicine, 35, 239-244. 
Hosoda, M., Stone-Romero, E., \& Coats, G. (2003). The effects of physical attractiveness on job-related outcomes: A meta-analysis of experimental studies. Personnel Psychology, 56, 431-462.

Houseknecht, S. K., \& Spanier, G. B. (1980). Marital disruption and higher education among women in the United States. The Sociological Quarterly, 21, 375-389.

Hume, D. K., \& Montgomerie, R., (2001). Facial attractiveness signals different aspects of "quality" in women and men. Evolution and Human Behavior, 22, 93-112.

Jackson, L. A. (1992). Physical appearance and gender: Sociobiological and sociocultural perspectives. Albany, N.Y: State University of New York Press.

Jaeger, M. M. (2011). “A thing of beauty is a joy forever?” Returns physical attractiveness over the life course. Social Forces, 89, 983-1003.

Jankowiak, W.R., \& Fischer, E.F. (1992). A cross-cultural perspective on romantic love. Ethnology, 31, 149-155.

Kerckhoff, A. C., \& Davis. K. E. (1962). Value consensus and need complementarity in mate selection. American Sociological Review, 27, 295-303.

Langlois, J. H., Roggman, L. A., Casey, R. J., Ritter, J. M., Rieser-Danner, L. A., \& Jenkins, V. Y. (1987). Infant preferences for attractive faces: Rudiments of a stereotype? Developmental Psychology, 23, 363-369.

Lemay, E. J., Clark, M. S., \& Greenberg, A. (2010). Interpersonal Attraction Measure. Psyctests, doi:10.1037/t19199-000.

Lewis, R. A. (1972). A developmental framework for the analysis of premarital dyadic formation. Family Process, 11, 17-48.

Li, N. P., Bailey, J. M., Kenrick, D. T., \& Lisenmeier, J. W. (2002). The necessities and luxuries of mate preferences: Testing the tradeoff. Journal of Personality and Social Psychology, 82, 947-955.

Li, N. P., \& Kenrick, D. T. (2006). Sex similarities and differences in preferences for short-term mates: What, whether, and why. Journal of Personality and Social Psychology, 90, 468-489.

Li, N. P., Yong, J. C., Tov, W., Sng, O., Fletcher, G. J., Valentine, K. A.,...Balliet, D. (2013). Mate preferences do predict attraction and choices in the early stages of mate selection. Journal of Personality and Social Psychology, 105, 757-776. 
Lippa, R. A. (2007). The preferred traits of mates in a cross-national study of heterosexual and homosexual men and women: An examination of biological and cultural influences. Archives of Sexual Behavior, 36, 193-208.

Lips, H., \& Lawson, K. (2009). Work values, gender, and expectations about work commitment and pay: Laying the groundwork for the "motherhood penalty?" Sex Roles, 61, 667-676.

Lynn, M. (2009). Determinants and consequences of female attractiveness and sexiness: Realistic tests with restaurant waitresses. Archives of Sexual Behavior, 38, 737745 .

Malach Pines, A. (2001). The role of gender and culture in romantic attraction. European Psychologist, 6(2), 96-102.

Meltzer, A. L., McNulty, J. K., Jackson, G. L., \& Karney, B. R. (2014). Men still value physical attractiveness in a long-term mate more than women: Rejoinder to Eastwick, Neff, Finkel, Luchies, and Hunt (2014). Journal of Personality and Social Psychology, 106, 435-440.

McColl, R., \& Truong, Y. (2013). The effects of facial attractiveness and gender on customer evaluations during a web-video sales encounter. Journal of Personal Selling \& Sales Management, 33, 117-128.

Morrow, P.C. (1990). Physical attractiveness and selection decision making. Journal of Management, 16, 45-60.

Murstein, B. I. (1980). Mate selection in the 1970's. Journal of Marriage and Family, 42, 777-792.

Nash, R., Fieldman, G., Hussey, T., Lévêque, J., \& Pineau, P. (2006). Cosmetics: They influence more than Caucasian Female Facial Attractiveness. Journal of Applied Social Psychology, 36, 493-504.

O'Sullivan, L. F., \& Vannier, S. A. (2013). Playing the field? Does actual or perceived relationship status of another influence ratings of physical attractiveness among young adults. Canadian Journal of Behavioral Science, 45, 210-219.

Peck, H., \& Peck, S. (1970). A concept of facial esthetics. The Angle Orthodontist, 40(4), 284-317.

Perrett, D. I., Burt, D. M., Penton-Voak, I. S., Lee, K. J., Rowland, D. A., \& Edwards, R. (1999). Evolution and Human Behavior, 20, 295-307. 
Pierce, C.A. (1996). Body height and romantic attraction: A meta-analytic test of the male-taller norm. Social Behavior and Personality, 24, 143-149.

Reiss, I. L. (1960). Toward a sociology of the heterosexual love relationship. Marriage and Family Living, 22, 139-145.

Roberts, B. W., \& Robins, R. W. (2000). Broad dispositions, broad aspirations: The intersection of personality traits and major life goals. Personality and Social Psychology Bulletin, 26, 1284-1296.

Rothman, M. (2014). George Clooney on fiancée Amal Alamuddin: 'I'm marrying up'. $A B C$ News. Retrieved from http://abcnews.go.com/Entertainment/george-clooneyfiancee-amal-alamuddin-im-marrying/story?id=24646100.

Sacco, D. F., Hugenberg, K., \& Kiel, E. J. (2013). Facial attractiveness and helping behavior beliefs: Both attractive and unattractive targets are believed to be unhelpful relative to moderately attractive targets. Social Psychology, 1, 1-12.

Sadalla, E. K., Kenrick, D. T., and Vershure, B. (1987). Dominance and heterosexual attraction. Journal of Personality and Social Psychology, 52, 730-738.

Sanday, P. R. (1981). Female power and male dominance: On the origins of sexual inequality. New York: Cambridge University Press.

Sappenfield, B. R., \& Baloch, B. (1970). Perceived attractiveness of social stimuli as related to their perceived similarity of self. Journal of Psychology, 74, 105-111.

Saxton, T. K., Burris, R. P., Murray, A. K., Rowland, H. M., \& Roberts, S. C. (2009). Face, body and speech cues independently predict judgment of attractiveness. Journal of Evolutionary Psychology, 7, 23-35.

Schmidt, K., Levenstein, R., \& Ambadar, Z. (2012). Intensity of smiling and attractiveness as facial signals of trustworthiness in women. Perceptual and Motor Skills, 114, 964-978.

Shackelford, T. K., \& Larsen, R. J. (1999). Facial attractiveness and physical health. Evolution and Human Behavior, 20, 71-76.

Shoemake, E. G. (2007). Human mate selection theory: An integrated evolutionary and social approach. Journal of Scientific Psychology, 1, 35-41.

Singh, D. (1993a). Mating strategies of young women: Role of physical attractiveness. Journal of Sex Research, 41, 43-54. 
Singh, D. (1993b). Adaptive significance of female physical attractiveness: Role of waistto-hip ratio. Journal of Personality and Social Psychology, 65, 293-307.

Sprecher, S. (1989). The importance to males and females of physical attractiveness, earning potential, and expressiveness in initial attraction. Sex Roles, 21, 591-607.

Sprecher, S., Sullivan, Q., \& Hatfield, E. (1994). Mate selection preferences: Gender differences examined in a national sample. Journal of Personality and Social Psychology, 66, 1074-1080.

Sui, J., \& Liu, C. H. (2009). Can beauty be ignored? Effects of facial attractiveness on covert attention. Psychonomic Bulletin and Review, 16, 276-281.

Swami, V., Smith, J., Tsiokris, A., Georgiades, C., Sangareau, Y., Tovée, M. J., \& Furnham, A. (2007). Male physical attractiveness in Britain and Greece: A crosscultural study. The Journal of Social Psychology, 147, 15-26.

Swami, V., \& Tovée, M. J. (2005). Female physical attractiveness in Britain and Malaysia: A cross-cultural study. Body Image, 2, 115-128.

Swami, V., Tovée, M. J., \& Furnham, A. (2008). Does financial security influence judgments of female physical attractiveness? The Journal of Socio-Economics, 37, 1363-1370.

Townsend, J. M. (1987). Sex differences in sexuality among medical students: effects of increasing socioeconomic status. Archives of Sexual Behavior, 16, 425-444.

Townsend, J. M., \& Levy, G. D. (1990). Effects of potential partners' costume and physical attractiveness on sexuality and partner selection. Journal of Psychology: Interdisciplinary and Applied, 124, 371-389.

Townsend, J. M., \& Wasserman, T. (1998). Sexual attractiveness: Sex differences in assessment and criteria. Evolution and Human Behavior, 19, 171-191.

Trivers, R. L. (1972). Parental investment and sexual selection. In B. G. Campbell (Ed.), Sexual selection and the descent of man (pp. 136-179). Chicago, IL: Aldine.

U.S. Bureau of Labor Statistics. (2014). United States Bureau of Labor Statistics. Retrieved from http://www.bls.gov/.

Van Leeuwen, M. L., \& Macrae, C. N. (2004). Is beautiful always good? Implicit benefits of facial attractiveness. Social Cognition, 22, 637-649. 
Vigil, J. M., Geary, D. C., \& Byrd-Craven, J. (2006). Trade-offs in low-income women's mate preferences. Special Issue: Human Sperm Competition, 17, 319-336. 


\section{Appendix A}

\section{Sample Stimuli Facial Photographs}

(Ebner, Riediger, \& Lindenberger, 2010)

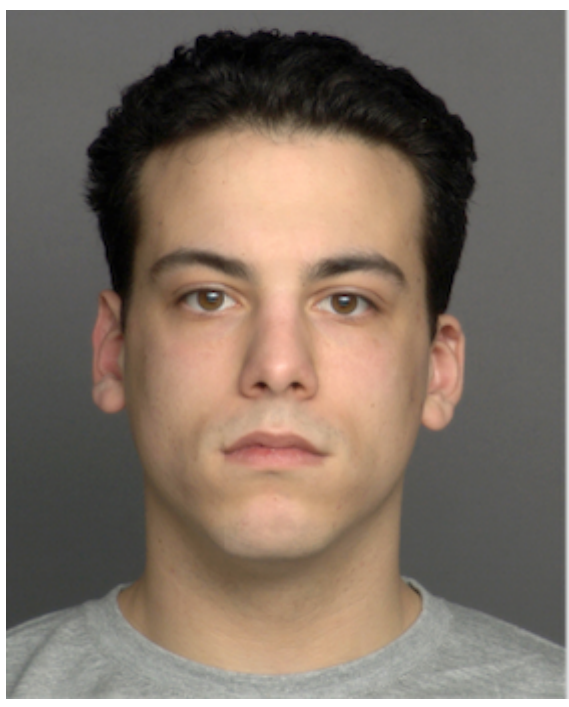

Physically Unattractive Male Stimuli

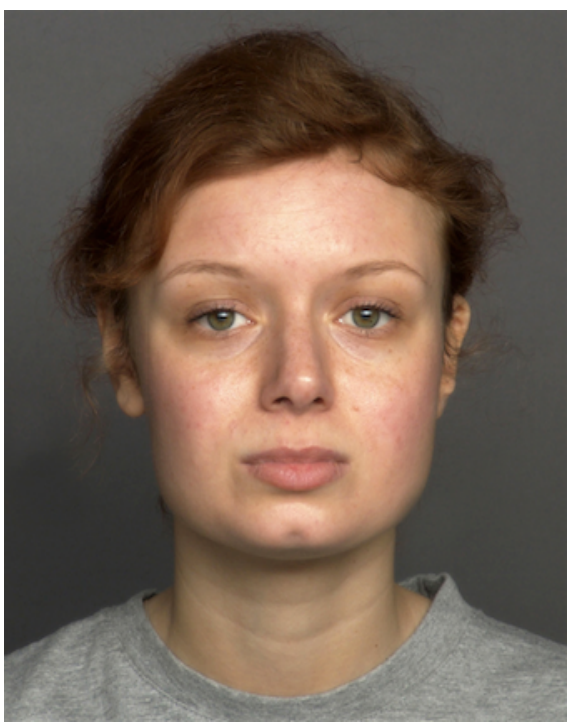

Physically Unattractive Female Stimuli

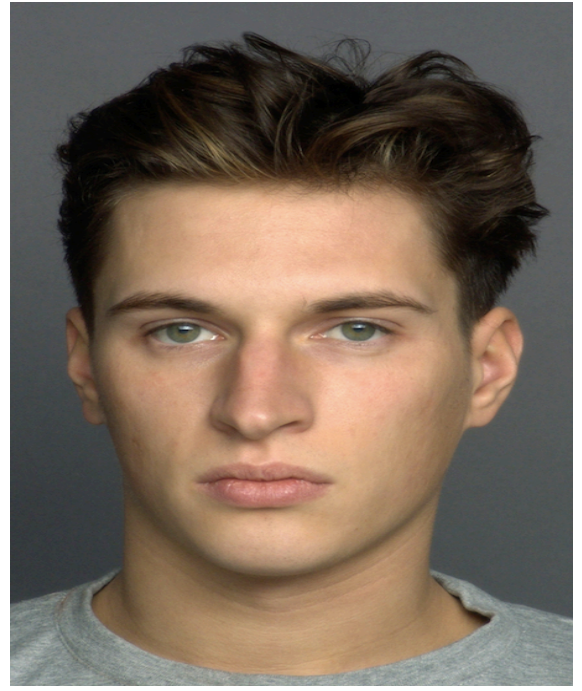

Physically Attractive Male Stimuli

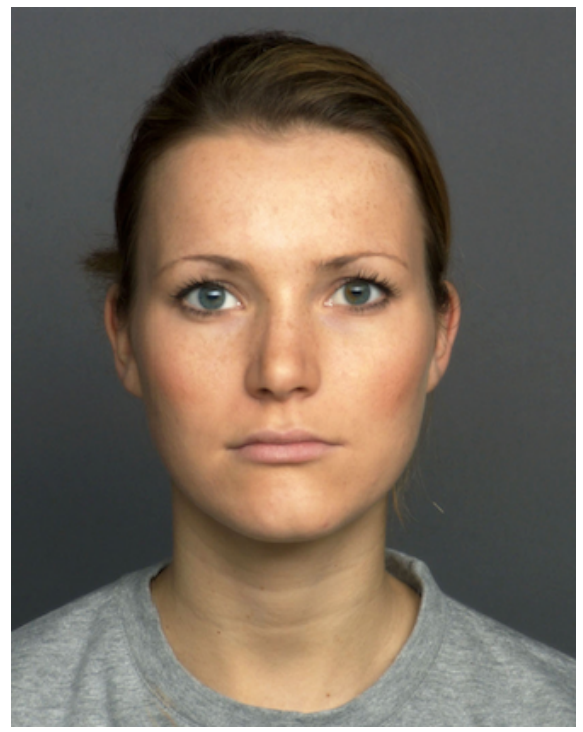

Physically Attractive Female Stimuli

Note. Permission for use granted by the FACES database of the Max Planck Institute for Human Development on July 3, 2014. 


\section{Appendix B}

Socioeconomic Status Descriptions

$\underline{\text { Low socioeconomic status profiles }}$

Profession: Retail Sales Worker

Annual Salary: \$21,410

Profession: Library Assistant

Annual Salary: \$26,800

Profession: Waiter/Waitress

Annual Salary: \$18,540

Profession: Bank Teller

Annual Salary: \$24,940

High socioeconomic status profiles

Profession: Medical Doctor

Annual Salary: \$187,200

Profession: Financial Manager

Annual Salary: \$109,740

Profession: Lawyer

Annual Salary: $\$ 113,530$

Profession: Dentist

Annual Salary: \$149,310 


\section{Appendix C}

\section{Background Questionnaire}

\section{Part One}

1) How old are you?

2) What gender do you identify with? Male__ Female __ Other

3) What ethnicity do you identify most with? (Choose one) White/Caucasian

African American

Middle Eastern

Asian

Pacific Islander

Hispanic

Other (please identify)

4) What is your sexual orientation? (Choose one)

Heterosexual

Homosexual

Bisexual

Other 
Part Two

5) What is your current annual income?

Not currently working

$1-20,000$

$20,001-40,000$

$40,001-60,000$

$60,001-80,000$

$80,001+$

6) Please state below if there are any issues/concerns you have regarding the study. If none, leave blank. 


\section{Appendix D}

Modified Interpersonal Attraction Measure (Lemay, Clark, \& Greenberg, 2010)

\section{Subjective judgments of attractiveness}

-How physically unattractive or physically attractive is this person?

(1=Very unattractive; $7=$ Very attractive $)$

Perceivers' own affiliation motivation (OMITTED FROM ANALYSES)

Interest in increasing acquaintanceship

-Based on your first impression, how interested would you be in getting to know this person?

$(1=$ Not at all interested; $7=$ Extremely interested $)$

Anticipated friendly behavior

-Based on your first impression, how would you treat this person?

$(1=$ Very friendly; $4=$ Neutral; $7=$ Very unfriendly $)$

Anticipated liking

-Based on your first impression, to what extent would you like this person?

$(1=$ Strongly dislike him or here; $4=$ Neutral; $7=$ Strongly like him or her $)$

Perceived targets' interpersonal traits (OMITTED FROM ANALYSES)

-Based on your first impression, please rate this person's personality

Kindness $(1=$ Very cruel; $4=$ Neutral; $7=$ Very kind $)$

Generosity ( 1 = Very giving; 4 = Neutral; 7 = Very selfish $)$

Extraversion ( 1 = Very outgoing; $4=$ Neutral; $7=$ Very shy $)$

Warmth $(1=$ Very cold; $4=$ Neutral; $7=$ Very warm 


\section{Appendix E}

Agreement to Participate in Research

Responsible Investigator(s): Sherrie Jagolino

Title of Protocol: First Impressions

1. You have been asked to participate in a research study investigating perception upon first impressions.

2. You will be asked to give a rating after viewing facial photographs on a computer. The study will last approximately 10-15 minutes.

3. There are no foreseeable risks or discomforts.

4. You will receive no direct benefits from participating in this study.

5. Although the results of this study may be published, no information that could identify you will be included in any reports of this study.

6. No compensation is provided for participation in this study.

7. Questions about this research may be addressed to Sherrie Jagolino at s.jagolino@gmail.com. This e-mail address is being protected from spambots. You need JavaScript enabled to view it. Complaints about this research may be presented to Dr. Arlene Asuncion, PhD at arlene.asuncion@sjsu.edu. Questions about a research subject's rights, or research related injury may be presented to Pamela Stacks, $\mathrm{PhD}$, Associate Vice President, Graduate Studies and Research at (408) 924-2427.

8. No service of any kind, to which you are otherwise entitled, will be lost or jeopardized if you choose not to participate in the study.

9. Your consent is being given voluntarily. You may refuse to participate in the entire 
study or in any part of the study. If you decide to participate in the study, you are free to withdraw at any time without any negative effect on your relations with San José State University. Partial completion of the study, however, will result in partial credit.

10. At the time that you agree to this consent form, you have the option to print out a copy of it for your records. 